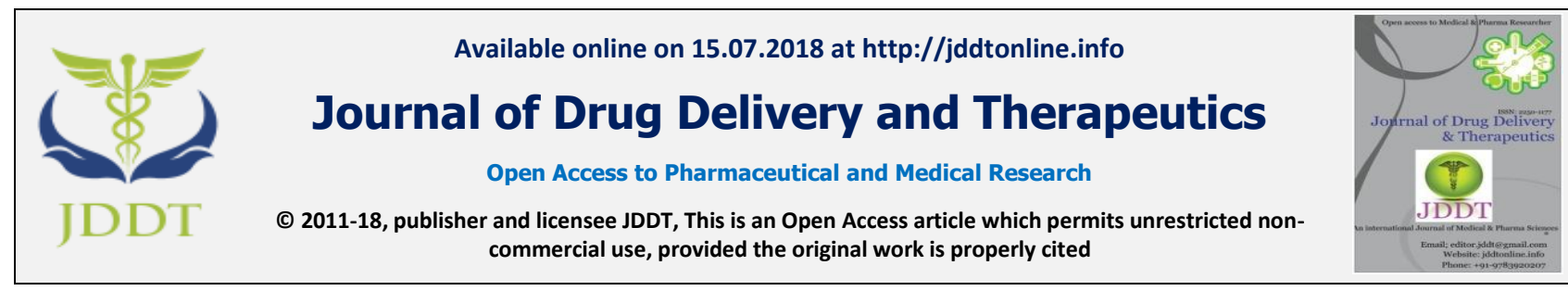

Open $\odot$ Access

Research Article

\title{
FORMULATION DEVELOPMENT OF SUSTAINED RELEASE INTRA- ARTICULAR INJECTION OF ANALGESIC DRUG
}

\author{
Mirajkar Reshma*, Kurkute Rutuja, Madgulkar Ashwini \\ Department of Pharmaceutics, AISSMS College of Pharmacy, Near RTO, Kennedy Road, Pune 411001, Maharashtra, India
}

\begin{abstract}
The purpose of this study was to formulate and evaluate Parenteral Intraarticular Sustained-Release Formulation of an analgesic drug using the technology of in situ forming gel, based on temperature change mechanism in order to reduce the frequency of dosing and increase patient compliance in the treatment of knee pain. The formulation was optimized, prepared, filled aseptically, sterilized and evaluated for prerequisites of parenteral and other parameters like gelation temperature, gel strength, viscosity, drug content, in vitro and in vivo studies and stability studies. It was prepared using cold method and optimized by 32 factorial design, comprising of drug, Pluronic F127, HPMC K 100M and HPMC K4M was found to be clear, colorless, isotonic, sterile, pH as 6.8-7, viscosity of 1800 cps, syringeable through 18 gauze needle, forming a stable in-situ gel at knee joint temperature having gel strength of $43.80 \mathrm{gm} / \mathrm{cm}$ showing a drug release of $95.88 \%$ in phosphate buffer $\mathrm{pH} 7.4$ at $120 \mathrm{hrs}$. The sterile formulation packed in transparent ampoule was found to the stable with most suitable storage condition at the refrigerator temperature. Thus a biocompatible, stable parenteral formulation was developed which can be an alternative and convenient approach to the patients that require frequent parenteral administration, reducing the frequency of dosing and ultimately increasing patient compliance and comfort.
\end{abstract}

Keywords: Tramadol HCL, In situ gel, Pluronic F127, intra-articular

Article Info: Received 17 April, 2018; Review Completed 18 June 2018; Accepted 22 June 2018; Available online 15 July 2018

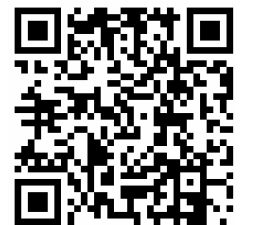

Cite this article as:

Mirajkar R, Kurkute R, Madgulkar A, Formulation development of sustained release intra-articular injection of analgesic drug, Journal of Drug Delivery and Therapeutics. 2018; 8(4):209-217 DOI: http://dx.doi.org/10.22270/jddt.v8i4.1770

*Address for Correspondence:

Reshma Mirajkar, Department of Pharmaceutics, AISSMS College of Pharmacy, Near RTO, Kennedy Road, Pune 411001, Maharashtra, India

\section{INTRODUCTION}

Analgesics are common medications used for moderate and severe pain given by a variety of different routes of administration which are effective for both nociceptive and neuropathic pain symptoms. Tramadol is a widely used analgesic that acts as a $\mu$-opioid receptor agonist, altering the perception and response to pain, centrally and peripherally which are used in moderate to severe pain, available as immediate-release/orally disintegrating tablets (400 mg/day), extended-release tablets (300 $\mathrm{mg} /$ day). It is widely used in case of knee pain either as in oral dosage forms or in injections forms $(100 \mathrm{mg} /$ day).

One of the treatments for knee pain involves the intraarticular injections which are an attractive treatment for knee pain. An intraarticular route has been underestimated in the past years in the treatment of jointrelated disorders, and reliance on the systemic routes of administration prevailed instead. It involves the injection of medications like non-steroidal anti-inflammatory drugs (NSAIDS), hyaluronic acid and corticosteroids into a joint space, usually to reduce inflammation, pain and increasing function. These conventional treatments suffer from the drawbacks of fast drug leakage in joint cavity, provide only short-term pain relief, quick release and frequent dosing or multiple injections are needed. These drawbacks can be overcome with sustained drug delivery systems. Development of new sustained release injectable formulation has received considerable attention due to many advantages of these systems such as localized and site-specific action, prolonged delivery period, decreased drug dosages, reduction of side effects and improved patient comfort and compliance over the 
conventional parenteral delivery. Such reduction in the frequency of drug dosing is achieved, in practice, by the use of specific formulation technologies that guarantee that the release of the active drug substance happens in a slow and predictable manner. In situ gel forming technology is one of the widely used systems that are fluids at room temperature and solidify when introduced into the body in a minimally invasive manner due to stimuli like $\mathrm{pH}$ change or temperature modulation. Advantages of this technology are the less complicated fabrication, a deliverance of accurate dose, ease of administration, reduced frequency of administration, improved patient compliance and comfort. One of the widely used polymer to achieve this is poloxamer 407 a thermosensitive polymer having the unique characteristic of phase transition i.e. sol-gel at body temperature $2,3,4$

Currently sustained release intraarticular injections are available in the market that gives the reduction in pain but has drawbacks like effects in the injected knee such as infection (with pain, swelling, and restricted motion) or joint damage, weakening of bones, inflammation at injection site. 5,6

Thus our overall objective was to research and formulate Sustained release intraarticular injection of analgesic drug tramadol $\mathrm{HCl}$ using in-situ gel forming technology based on thermosensitive polymer, aiming to achieve a prolonged release of the drug over a period of 5 days. This would have the advantage of administration of a drug to the target site (IA) to overcome the drawbacks of conventional and achieve the advantage of administrating the dosage once a week and reducing the frequency of injections.

\section{MATERIALS AND METHOD}

\section{Materials}

Tramadol HCL was obtained as a gift sample from Emcure Pharmaceuticals Pune. PluronicF127 was provided by Ana lab fine chemical, Mumbai.Hydroxy propyl methyl celluloseK100M, K4M (HPMCK 100M, HPMC K4M) was provided by Chemica-biochemicreagents, Otto chemie,Pvt.Ltd.

\section{Method}

\section{Optimization study -}

A response surface statistical experimental design was used to optimize the effect of different independent factors on response. The responses were investigated using a Box-Behnken statistical experimental design using Design-expert software ${ }^{\circledR} 11$ (Stat-Ease, Inc., USA)

This design was based on a $3^{2}$ factorial design, three replicates of the central run, leading to 9 sets of experiments, enabling each experimental response to be optimized. Different batches were prepared with different independent variables at different levels and responses. The criterion for selection of optimum formulations was based on the gelation at body temperature and highest gel strength to remain stable for prolonged period of time i.e. for 5 days.

Table 1: Formulation combination as per the $3^{2}$ full factorial designs

\begin{tabular}{|l|c|c|}
\hline Formulation code & HPMC K100M \% (W/V) & HPMC K4M \% (W/V) \\
\hline F1 & 2 & 1.5 \\
\hline F2 & 2 & 1 \\
\hline F3 & 2 & 0.5 \\
\hline F4 & 1.5 & 1.5 \\
\hline F5 & $\mathbf{1 . 5}$ & $\mathbf{1}$ \\
\hline F6 & 1.5 & 0.5 \\
\hline F7 & 1 & 1.5 \\
\hline F8 & 1 & 1 \\
\hline F9 & 1 & 0.5 \\
\hline
\end{tabular}

The quality of the fitted model was expressed by the coefficient of determination $\mathrm{R}^{2}$, and its statistical significance was checked by an F-test (analysis of variance) at the 5\% significance level. The statistical significance of the regression coefficients was determined by using the t-test (only significant coefficients with $\mathrm{p}$-value $<0.05$ are included). The optimum processing conditions were obtained by using graphical and numerical analysis based on the criteria of the desirability function and the response surface. ${ }^{7}$

\section{Preparation of Formulation}

The formulation was prepared by using cold method. Drug was dissolved in water followed by addition of thermosensitive polymer Pluronic F127, stirred and kept in refrigerator at $4 \mathrm{c}$ for $24 \mathrm{hrs}$ to dissolve completely and form a clear solution. The other excipients like copolymer HPMC K100M, HPMC K4M and tonicity adjusting agent $\mathrm{NaCl}$ were added to this solution and stirred continuously to dissolve to give complete clear viscous solution which was filled aseptically in transparent glass ampoules $2 \mathrm{ml}$ and sterilized by autoclaving at $121^{\circ} \mathrm{C}$ at $15 \mathrm{psi}$ for $20 \mathrm{~min}$ and stored at refrigerator condition. $8,9,10,11$

\section{Evaluation of Formulation}

\section{Appearance \& pH}

The optimized formulation was visually checked for its appearance and $\mathrm{pH}$. The $\mathrm{pH}$ of the sol form was measured using standardized digital $\mathrm{pH}$ meter (Deluxe $\mathrm{pH}$ meter 101/EI) at room temperature by taking adequate volume in a $10 \mathrm{ml}$ beaker. $^{12}$ 


\section{Gelation Temperature}

Gelation temperature was determined by modification of Miller and Doravan technique. A $2 \mathrm{ml}$ aliquot of gel was transferred to test tubes immersed in a cryostatic water bath at $20^{\circ} \mathrm{C}$ and sealed with aluminum foil. The temperature of water circulation bath was increased with increments of $1{ }^{\circ} \mathrm{C}$ and left to equilibrate for $5 \mathrm{~min}$. at each new setting. The samples were examined for gelation which was said to have occurred when the meniscus would no longer move upon tilting through $90^{\circ}$ angle. $8,9,10$

\section{Gel strength}

Gel strength was determined by Surimi test using Texture Analyzer (Texture Pro CT V1.4). Formulation $(20 \mathrm{ml})$ was placed in $25 \mathrm{ml}$ beaker and gelled using heating plate at $32^{\circ} \mathrm{C}$. The probe (TA 3/100) was allowed to traverse the gel up to $1 \mathrm{~cm}$ at a speed of $1 \mathrm{~mm} / \mathrm{s}$. The load reading was taken in $\mathrm{g} / \mathrm{cm}$ for gel strength. ${ }^{13}$

\section{Viscosity}

Viscosity was measured on Brookfield viscometer using RV (spindle no. 21) and T-type helipath spindle (spindle no. S21). Rheological behaviour was analyzed by subjecting the sample at temperature ambient temperature and $32^{\circ} \mathrm{C}$ and variable shear stress. ${ }^{14}$

\section{Osmolality}

The samples were subjected to osmolality test using an Osmometer (Model 3250, Version 2.4). ${ }^{12}$

\section{Syringiablity}

Syringiablity of the formulations was assured using 18 to 22 gauge needles. Formulation was withdrawn into identical $5 \mathrm{ml}$ plastic syringes placed with needles to a constant volume $(1 \mathrm{ml})$. The solutions which were easily passed from a particular syringe were termed as pass and the ones which were difficult to pass were termed as fail. $^{12}$

\section{Drug content estimation}

The quantity of formulation equivalent to $10 \mathrm{mg}$ of Tramadol HCL was taken and diluted with $10 \mathrm{ml}$ of methanol $(1000 \mu \mathrm{g} / \mathrm{ml})$ and was diluted up to $10 \mathrm{ml}$ with methanol to get a stock solution of $(100 \mu \mathrm{g} / \mathrm{ml})$. From this stock solution, a solution of $50 \mu \mathrm{g} / \mathrm{ml}$ was prepared and analyzed by UV spectrophotometer and HPLC. The concentration of the drug present in the formulation was computed from the calibration curve using the equation $\mathrm{y}=\mathrm{mx}+\mathrm{c}^{15}$

\section{Sterility Testing}

Sterility testing was carried out as per the IP 2014. The formulation was incubated for not less than 14 days at $30-35^{\circ} \mathrm{C}$ in the alternate fluid thioglycolate medium to find the growth of bacteria \& at $20^{\circ} \mathrm{C}-25^{\circ} \mathrm{C}$ in Soya bean casein digest medium to find the growth of fungi in formulation. The test was performed using positive and negative controls. ${ }^{16,17}$

\section{In-vitro Drug Release Studies}

The in vitro drug release studies of Tramadol HCL insitu gel forming sustained release injectable were carried out using Orbital Shaking Incubator (REMI model) to maintain the temperature at $32^{\circ} \mathrm{C}$ and agitated at $30 \mathrm{rpm}$ for 5 days. This speed was kept slow enough to avoid the breaking of gelled formulation under mild agitation conditions similar to physiological conditions. The dissolution medium used was phosphate buffer ( $\mathrm{pH}$ 7.4). $1 \mathrm{ml}$ of aliquots was withdrawn at specific time intervals $(1,24,48,72,96,120 \mathrm{hrs})$ and replenished with fresh medium to maintain the sink conditions. Aliquots withdrawn were filtered, suitably diluted and analyzed using UV spectrophotometer (V-530, Jasco) at 271nm. Percentage cumulative drug release (\% CDR) was calculated using an equation obtained from a calibration curve. $^{18,19}$

\section{Determination of drug release kinetics}

To describe the kinetics of the drug release from the sustained release in-situ gel, mathematical models such as Zero-order, First-order, Higuchi, Hixon-Crowell, Korsmeyer-peppas models were evaluated by modeldependent (curve fitting) method using PCP Disso V2.08 software. ${ }^{20,21}$

\section{Accelerated Stability study}

Stability studies were carried out on optimized formulation according to International Conference on Harmonization (ICH) guidelines. A sufficient quantity of formulations were kept at room temperature i.e. at $25^{\circ} \mathrm{C} \pm 2{ }^{\circ} \mathrm{C} / 60 \% \pm 5 \% \mathrm{RH}$, refrigerator i.e. at $5^{\circ} \mathrm{C} \pm 3^{\circ} \mathrm{C}$ and accelerated conditions $\left(40^{\circ} \mathrm{C} \pm 5^{\circ} \mathrm{C} / 75 \pm 5 \% \mathrm{RH}\right)$ for 1 month. After 1 month samples were evaluated for appearance, $\mathrm{pH}$, clarity, gelation temperature, \% drug content and in vitro drug release. ${ }^{22,23}$

\section{RESULTS AND DISCUSSIONS}

\section{Optimization study}

The design of experiment (DOE) is an approach in which process variables are first screened and then optimized to determine best settings for the variables. The full factorial design is a quadratic design which requires 3 levels $(-1,0,+1)$ for each factor. In which the concentration of HPMC K100M and HPMC K 4M were selected as the independent variables whereas Gel strength and Drug release were selected as the dependent variables. The interactions between the factors were demonstrated using 3-D graphs. The experimental values obtained were compared with those predicted by the mathematical models. The data generated is given in Table 3 which was analyzed using Design Expert software version 11.0 and polynomial equations were obtained for the same. 
Table 2: $3^{2}$ experimental design with response

\begin{tabular}{|l|c|c|c|}
\hline $\begin{array}{c}\text { Formulation } \\
\text { code }\end{array}$ & $\begin{array}{c}\text { Gel strength } \\
\text { (gm/cm) }\end{array}$ & $\begin{array}{c}\text { \% Drug release } \\
\text { (At 96 hrs) }\end{array}$ & $\begin{array}{c}\text { \% Drug release (At } \\
\mathbf{1 2 0} \text { hrs) }\end{array}$ \\
\hline F1 & 46.50 & 50.61 & 62.18 \\
\hline F2 & 42.80 & 61.04 & 73.06 \\
\hline F3 & 41.00 & 93.93 & - \\
\hline F4 & 44.10 & 55.70 & 78.90 \\
\hline F5 & $\mathbf{4 3 . 8 0}$ & $\mathbf{8 4 . 6 5}$ & $\mathbf{9 7 . 0 5}$ \\
\hline F6 & 42.95 & 95.56 & - \\
\hline F7 & 41.70 & 54.94 & 68.65 \\
\hline F8 & 42.30 & 100 & - \\
\hline F9 & 41.40 & 100 & - \\
\hline
\end{tabular}

\section{Response Surface plots:}

\section{(1) Gel strength}

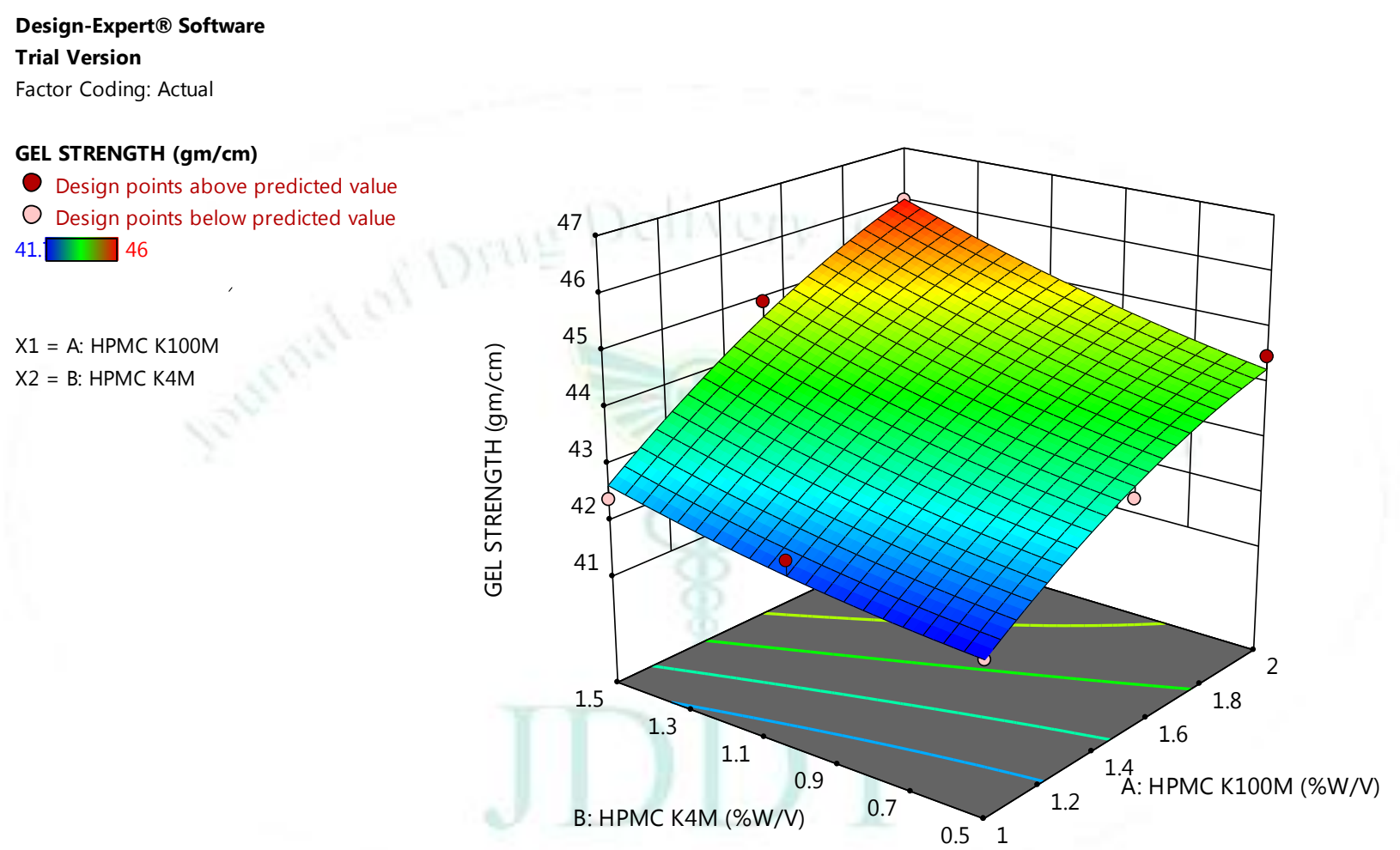

Figure 1: Response surface of gel strength

Above response surface plot showed that as the concentration of HPMCK100M increases, the gel strength increases. Similarly for other polymer to withstand the various body shear forces, gel must have the sufficient gel strength which was imparted by the addition of HPMC K100M and HPMC K4M.

In the equation, $\mathrm{A} \& \mathrm{~B}$ having positive effect on gel strength. The interaction terms A \& B have synergistic effect on gel strength.

Analysis of variance has been calculated to analyze the accessibility of the model. The $F$ distribution is a probability distribution used to compare variances by examining their ratio. If they are equal then $F$ value would equal to one. The $F$ value in the ANOVA table is the ratio of model mean square (MS) to the appropriate error mean square. The larger the ratio, the larger the $F$ value and the more likely that the variance contributed by the model is significantly larger than random error. As a general rule, if $p$-value is less than 0.05 , model parameter is significant.

On the basis of analysis of variance, the conclusion is that the selected model adequately represents the data for the formulation of prolonged release parenteral drug delivery system. Final Equation of gel strength in terms of Coded Factors

Gel strength $=+36.82+6.166 * \mathrm{~A}+0.983 * \mathrm{~B}+0.800 * \mathrm{~A} * \mathrm{~B}$ $+1.333 * \mathrm{~A}^{2}+0.5666 * \mathrm{~B}^{2} \ldots$ (1)

Where, A is concentration of HPMC K100M and B is the concentration of HPMC K4M. 
(2) Drug Release:
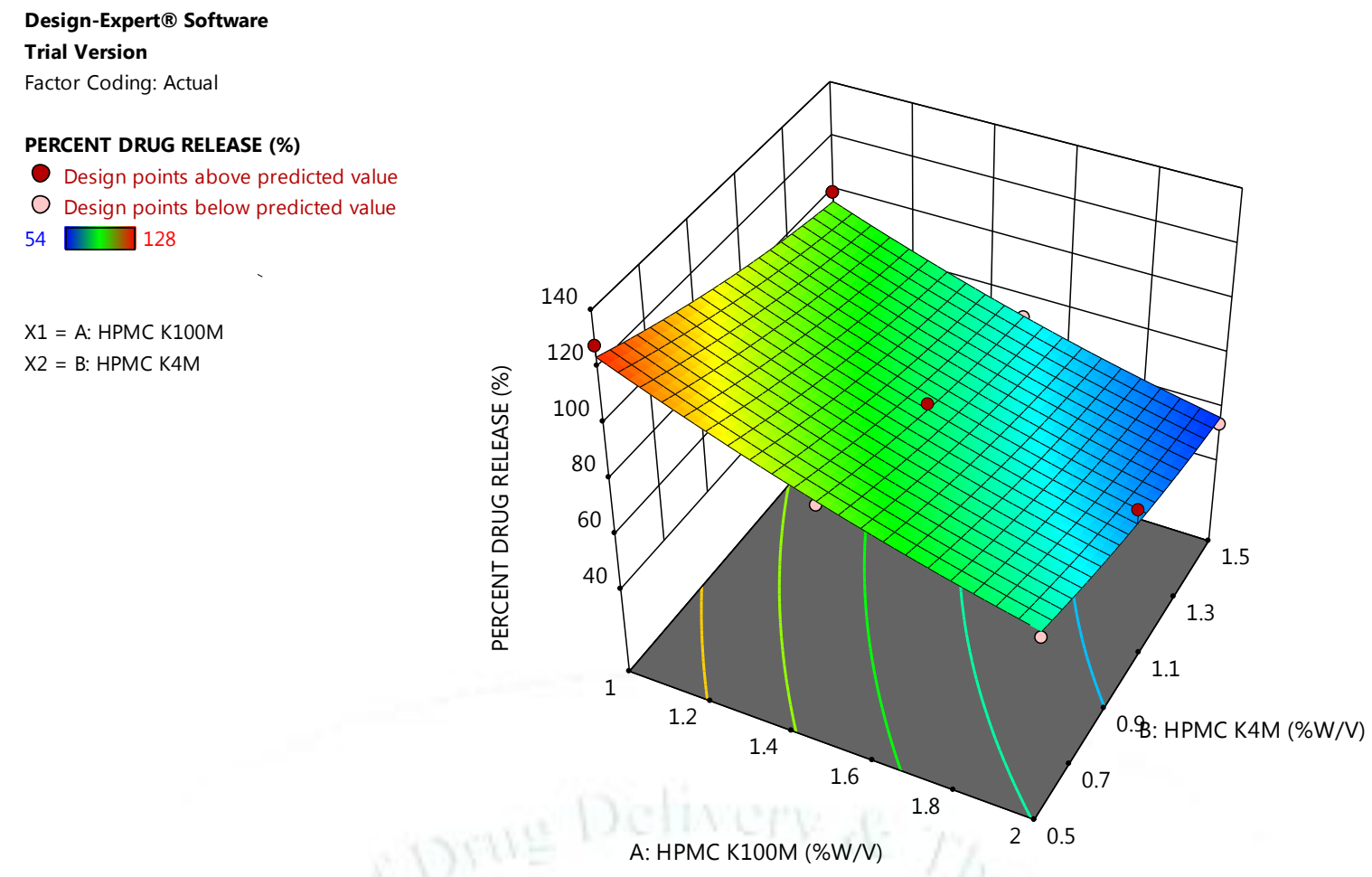

Figure 2: Response surface for Drug Release

Figure 2 shows the combined effect of HPMC K 100M and HPMC K4M on drug release. In order to obtain a sustained release over a 5 day period, it was necessary for the in situ gel formed to have a sufficient strength and stability. Alone HPMC K100M could not impart these parameters so HPMC $\mathrm{K} 4 \mathrm{M}$ was added as a copolymer to reduce the burst release. It is observed from the plot that concentration HPMC K $100 \mathrm{M}$ has pronounced effect on drug release because as the concentration of HPMC K100M increases, drug release gets sustain. 3D response surface plot for drug release showed that decreasing the concentration of HPMC K $100 \mathrm{M}$ at a higher level of HPMC K4M resulted in a lower degree of drug release.

Final Equation of Drug release in terms of Coded Factors:

Drug release $=+220-86.43^{*} \mathrm{~A}-$ $56.10 * \mathrm{~B}+5.300 * \mathrm{~A} * \mathrm{~B}+12.84 * \mathrm{~A}^{2}+11.62 * \mathrm{~B}^{2}$...

Where, A is concentration of HPMC K100M and B is the concentration of HPMC K4M. In this case, A and B were found to be significant model terms. The positive coefficient of $\mathrm{B}$ indicated that as the concentration of HPMC K $4 \mathrm{M}$ increased, the drug release also gets decreased. The negative sign of $\mathrm{A}$ is indicating that lower the concentration of HPMC K $100 \mathrm{M}$, the higher will be the drug release. The low coefficient of $\mathrm{A}$ indicated that HPMC K 100M concentration affected drug release to a greater extent than HPMC K $4 \mathrm{M}$ concentration. The positive coefficient for term $\mathrm{AB}$ for the combined effect of both factors was found to have a positive effect.

In order to find out the contribution of each component and their interaction, Analysis of Variance (ANOVA) was carried. The ANOVA analysis of the quadratic model showed that the model was significant $(p<0.05)$ which was also supported by the high $\mathrm{F}$ value and with the adequate Precision (ratio>4) was observed as shown in Table 3 and validation of the Response Surface Methodology are shown in Table 5.

Table 3: ANOVA studies

\begin{tabular}{|l|l|l|l|l|l|}
\hline $\begin{array}{l}\text { Response } \\
\text { variables }\end{array}$ & F value & P value & Adj R2 & Pred R2 & $\begin{array}{l}\text { Adequate } \\
\text { Precision }\end{array}$ \\
\hline Gel strength & 132.46 & 0.0018 & 0.9578 & 0.9367 & 31.26 \\
\hline \% Drug Release & 38.95 & 0.0051 & 0.97 .64 & 0.8854 & 18.957 \\
\hline
\end{tabular}

Table 4: Desirability function of optimized formulation

\begin{tabular}{|c|c|c|c|}
\hline Formulation code & $\begin{array}{c}\text { HPMC K100M } \\
(\% \mathrm{~W} / \mathrm{V})\end{array}$ & $\begin{array}{c}\text { HPMC K4M } \\
(\% \mathrm{~W} / \mathrm{V})\end{array}$ & Desirability \\
\hline F5 & 1.5 & 1 & 0.966 \\
\hline
\end{tabular}


Table 5: Validation of the Response Surface Methodology (RSM)

\begin{tabular}{|l|l|l|l|}
\hline Responses & Experimental value & Predicted value & \% Predicted error \\
\hline Gel strength & 43.80 & 44.50 & 0.7 \\
\hline \% drug release & 95.88 & 97.89 & 2.01 \\
\hline
\end{tabular}

\section{Appearance and pH}

All the formulations were clear and colourless. Terminal sterilization with autoclaving had no effect on physical and chemical properties of the formulation. The $\mathrm{pH}$ of the all the formulations was found to be between $6.8-7$. Moreover, the drug was found to be most stable in this $\mathrm{pH}$ range. Thus the formulation follows all the prerequisites of the parenteral dosage form.

\section{Gelation temperature}

The gelation temperature of the optimized formulation was found to be $32^{\circ} \mathrm{C}$. This temperature was sufficient to trigger in situ gel formation.

Pluronic F127 (P407) is a triblock copolymer with a central hydrophobic chain of polyoxypropylene (PPO) and two identical lateral hydrophilic chains of polyoxyethylene (PEO). As the concentration of Pluronic increases i.e. above micelle concentration, there is formation of micelle structure followed by aggregation of micelle. In cold water, hydrogen bonding between POP chains and water keeps the hydrophobic portions of the Pluronic apart and increase in temperature leads to disruption of the hydrogen bonds and occurrence of hydrophobic interactions and formation of gel. Therefore, the gelling properties of the Pluronic are dependent on percentage of hydrophobic portion. As the concentration of Pluronic F127 increases, the hydrophobic portion also increases resulting in formation of gel at lower temperature.

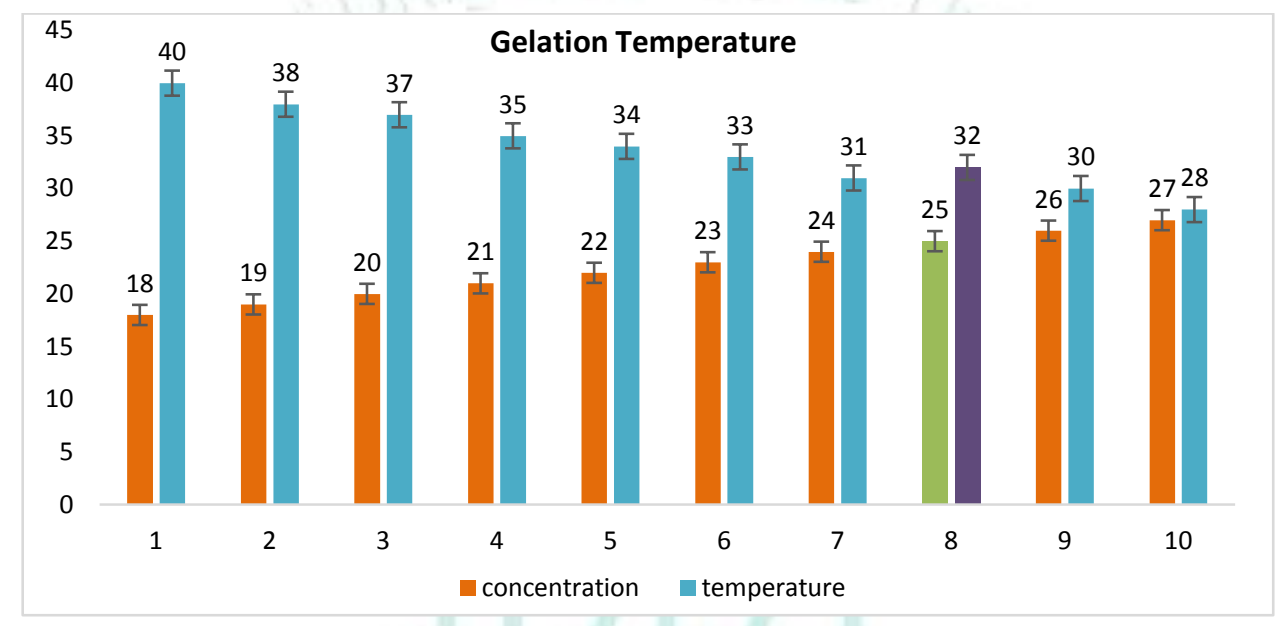

Figure 3: Effect of concentration of PF127 on gelation temp

\section{Gel strength}

Gel strength of optimized formulation was found to be $43.80 \mathrm{gm} / \mathrm{cm}$. Gel strength provides overview of the mechanical properties of gel. It also signifies the ability of gelled mass to withstand shear forces in the body for prolonged period of time. The Gel strength of formulation was important variable dependent on the concentration of gelling agent i.e. Pluronic F127. Pluronic F127 (25\%) reveals that it does not have sufficient gel strength so HPMCK100M were added which increases the gel strength, by forming hydrophobic interaction between the Pluronic F127 and HPMC K100M molecules.

\section{Viscosity}

The viscosity of optimized formulation was found to be $1800 \mathrm{cP}$. To administer the gel easily into the body it should possess optimal viscosity. Further the formulation undergoes sol to gel transition upon contact with body temperature. Pluronic F127 does not have sufficient viscosity to remain its integrity in body for prolonged period of time so HPMC K100M was added which impart viscosity in the formulation.

\section{Osmolality}

The Osmolality of the sample was found to be $313 \mathrm{mOsmol} / \mathrm{L}$

\section{Syringeability -}

The optimized formulation was easily passed through the needle gauge 18. This needle size was suitable for intraarticular injection.

\section{Drug content}

The percentage drug content in the formulation was calculated and found to be $97.85 \%$, indicating insignificant loss of drug during the formulation. 


\section{Sterility testing}

\section{Test for bacteria \& fungi}

Table 6: Observations for bacterial \& fungal growth

\begin{tabular}{|c|c|c|c|}
\hline \multirow{2}{*}{ Sample } & \multicolumn{2}{|c|}{ Observations } & \multirow{2}{*}{ Inference } \\
\cline { 2 - 3 } & Bacteria & Fungi & Growth \\
\hline Positive control & Turbid & Turbid & No growth \\
\hline Negative control & Clear & Clear & No growth \\
\hline Test sample & Clear & Clear & \\
\hline
\end{tabular}

No turbidity was observed after 14 days. It passes the sterility test. The formulation was found to be free from bacteria and fungi and hence suitable for parenteral and administration. Thus the sterility of the formulation may be attributed to aseptic process of preparation and filling the container and autoclaving at $121^{\circ} \mathrm{C}$ at 15 psi for 20 $\min$.

\section{In vitro Release study}

In vitro drug release study serves as an important tool in formulation and development. Drug release from Pluronic F127 gel into release medium was regulated by dissolution or diffusion of drug, depending upon experimental conditions. In vitro drug release of gel formulation was regulated by diffusion mechanism. Pluronic F 127 immediately converts into gel form at body temperature and when the formulation got exposed to the preheated phosphate buffer $\mathrm{pH} 7.4$ at $32^{\circ} \mathrm{C}$ it undergoes phase transition from sol-gel and forms a barrier for a drug release. As the time passes the outer layer become more hydrated and the polymer chains become fully relaxed and leading to erosion from the surface. As the concentration of HPMC K100M, HPMC K4 M increases drug release was retarded. Thus drug release was regulated by diffusion and erosion mechanism. Studies were performed in a triplicate which shows about $95.88 \%$ release after completion of 5 days.

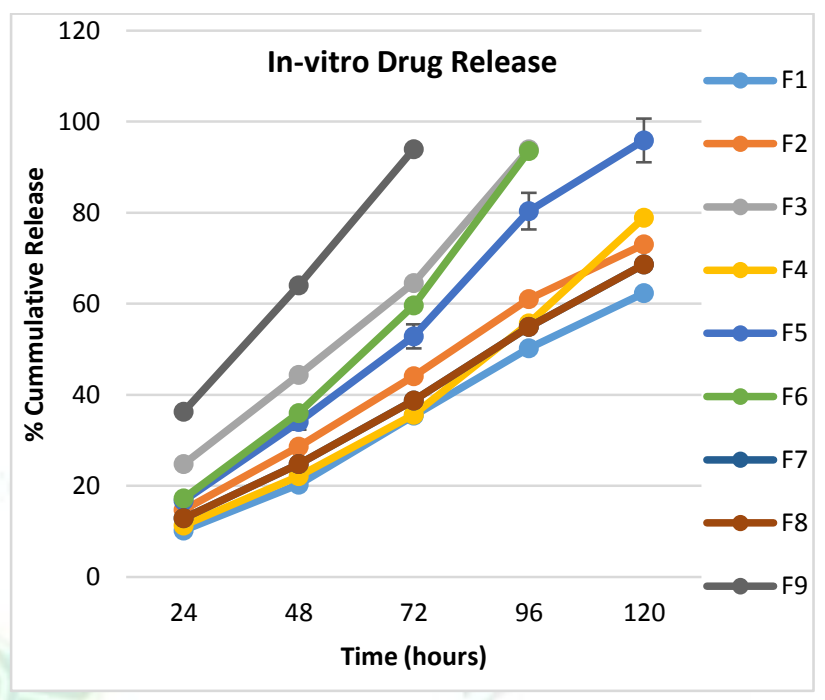

Figure: 4 In-vitro drug release

Kinetics and mechanism of drug release

Kinetic results shown in Table reveals that the best fit model for optimized batch was zeroorder kinetics as correlation coefficient ( $\mathrm{r} 2)$ values are higher than other release kinetics. The calculated $\mathrm{n}$ values from power law equation for drug release profiles were between 0.51190.7523 with a correlation coefficient $(\mathrm{r} 2)$ values $>0.93$, suggest that the optimized formulation followed nonFickian (anomalous) diffusion mechanism for drug release.

Table 7: Model for release kinetics

\begin{tabular}{|l|l|l|l|l|}
\hline Formulation F5 & Zero order & First order & Korsemeyer- Peppas order & Higuchi order \\
\hline R2 & 0.983 & 0.932 & 0.912 & 0.884 \\
\hline
\end{tabular}

\section{Accelerated Stability testing}

Stability studies indicate that optimized formulation was physically and chemically stable at ambient temperature i.e. at $25^{\circ} \mathrm{C} \pm 2{ }^{\circ} \mathrm{C} / 60 \% \mathrm{RH} \pm 5 \% \mathrm{RH}$ and at accelerated conditions $40^{\circ} \mathrm{C} \pm 2{ }^{\circ} \mathrm{C} / 75 \% \mathrm{RH} \pm 5 \% \mathrm{RH}$ and at refrigerator conditions i.e. at $5^{\circ} \mathrm{C} \pm 3^{\circ} \mathrm{C}$ for a period of 1 month. From stability studies, it was observed that the formulation of Tramadol HCL was stable at selected storage conditions with most suitable storage condition at the refrigerator temperature. It showed that there was no change in colour, gelation temperature but slightly decrease in $\mathrm{pH}$, gel strength and in vitro drug release profile at $40^{\circ} \mathrm{C}$. 
Table 8: Stability studies results after 1 month

\begin{tabular}{|c|c|c|c|c|}
\hline $\begin{array}{l}\text { Evaluation } \\
\text { parameters }\end{array}$ & Initial & $\begin{array}{c}\text { After storage at room } \\
\text { temperature }\end{array}$ & $\begin{array}{c}\text { After storage at } \\
40 \pm 2^{\circ} \mathrm{C} / 75 \pm 5 \%\end{array}$ & $\begin{array}{c}\text { After storage at } \\
\text { refrigerator temp }\end{array}$ \\
\hline Appearance & clear, colorless & clear, colorless & clear, colorless & clear, colorless \\
\hline pH & 7.3 & 7.1 & 6.8 & 7.2 \\
\hline Gelation temperature & $32^{\circ} \mathrm{C}$ & $32^{\circ} \mathrm{C}$ & $32^{\circ} \mathrm{C}$ & $32^{\circ} \mathrm{C}$ \\
\hline Gel strength $(\mathrm{gm} / \mathrm{cm})$ & 43.80 & 48.60 & 47.50 & 43.30 \\
\hline Drug content & 97.85 & 95.51 & 94.65 & 96.24 \\
\hline Syringeability & Passes & Passes & Passes & Passes \\
\hline $\begin{array}{l}\text { In vitro drug release at } 120 \\
\text { hrs after } 1 \text { month }\end{array}$ & 95.88 & 93.75 & 90.52 & 94.56 \\
\hline
\end{tabular}
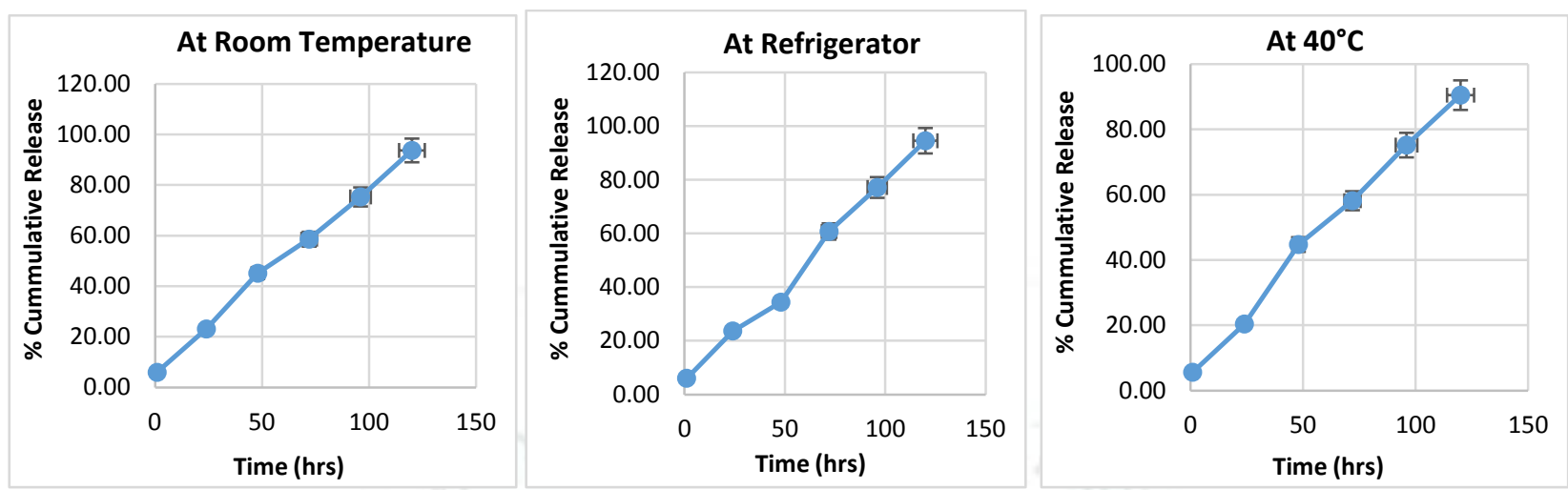

Figure: 5 In-vitro drug release after 1 month

\section{CONCLUSION}

Thus formulation of tramadol hydrochloride as an intraarticular in situ gelling parenteral drug delivery system is an alternative to the conventional and sustained release formulations owing to its ability to achieve a prolonged release of the drug over a period of 5 days with administration of a drug to the target site (IA) which overcome the drawbacks of conventional and

\section{REFERENCES}

1. [Internet]. Samples.jbpub.com. 2018 [cited 1 June 2018]. Available

from: http://samples.jbpub.com/9781449698843/9781449698843_ CH01_Print.pdf

2. Dong RK, Gi Young Park. Intraarticular Injections for the Treatment of Osteoarthritis. Focus on the Clinical Use of Several Regimens. INTECH Open Access Publisher; 2012. P. 67-100.

3. Egemen A, Hayrettin K, Isik A, Intraarticular injections (corticosteroid, hyaluronic acid, platelet rich plasma) for the knee osteoarthritis, World journal of orthopaedics, 2014,

4. Patel HR, Patel RP, Patel MM. Poloxamers: A pharmaceutical excipients with therapeutic behaviors, International Journal of PharmTech Research, 2009; 1(2):299-303

5. Zilretta Uses, Side Effects \& Warnings - Drugs.com [Internet]. Drugs.com. 2018 [cited 14 June 2018]. Available from: https://www.drugs.com/mtm/zilretta-injection.html

6. Diana Ernst R. Durolane Now Available to Treat Knee Osteoarthritis Pain [Internet]. MPR. 2018 [cited 14 June 2018]. Available from:

https://www.empr.com/news/durolane-knee-osteoarthritishyaluronic-acid-single-injection/article/748533/

7. Ranga S, Jaimini M, Sharma S, Chauhan B, Kumar A., A review on design of experiments (DOE), Review article. International Journal of Pharmaceutical and chemical sciences, 2014; 3(1):26-224. gives the advantage of administrating the dosage once a week and reduced the frequency of injections and improves patient compliance. The formulation involves less complicated fabrication and easy administration.

\section{ACKNOWLEDGEMENT}

The authors are a grateful to AISSMS College of Pharmacy, Pune, India

8. Abashzadeh S.,Dinarvand R.,Sharifzadeh M.,Hassanzadeh G, Amini M, Atyabi F. Formulation and evaluation of an in situ gel forming system for controlled delivery of triptorelin acetate. European journal of pharmaceutical sciences.2011; 4(4):514-521.

9. Pachpute D, Patil D, Chaudhari P. Formulation development and evaluation of in situ-nasal gel of levodopa. International Journal of pharmaceutical sciences. 2014; 4(5):449-453.

10. Jadhav P, Jadhav N, Hosmani A, Patil S.Development and evalution of in-situ thermoresponsive nasal gel system for Nardostachys jatamansi,Schlolars research library der pharmacia letter.2013; 5(2):113-125.

11. Sindhu SK, Gowda DV, Formulation and Evaluation of Injectable In-Situ Gelling Matrix System for Controlled Drug Release, Indian Journal of Advances in Chemical Science, 2014; 2:89-92.

12. Nikam K, Pawar M, Jadhav S, Bairagi V. Novel trends in parenteral drug delivery system, Review. International Journal of pharmacy and technology. 2013; 5(2):2549-2577.

13. Jun L, Bouchu W, Yazhou W. Thermo-sensitive polymers for controlled release drug delivery system. International Journal of Pharmacology, 2006; 2(5):513-519.

14. Chen J, Zhou R, Li L, Li B, Zhang X, Su J. Mechanical, Rheological and Release Behaviors of a Poloxamer 407/ Poloxamer 188/Carbopol 940 Thermosensitive Composite Hydrogel. Molecules. 2013; 18(10):12415-12425. 
15. Princely S. Design and evaluation of controlled release gentamycin incorporated gelatine alginate matrices for wound management. Scholars Research Library, 2015; 7 (1):145-153.

16. Indian Pharmacopoeia 2016. The Government of India ministry of health and family welfare. Published by The Indian Pharmacopoeia Commission. Ghaziabad, 7th ed. VolI. 59-66.

17. World Health Organization. Test for sterility. Document QAS/11.413. 2012,1-9

18. Erfani Jabarian L, Rouini M, Atyabi F, Foroumadi A, Nassiri $\mathrm{S}$, Dinarvand $\mathrm{R}$. In vitro and in vivo evaluation of an in situ gel forming system for the delivery of PEGylated octreotide. European Journal of Pharmaceutical Sciences, 2013; 48(12):87-96.
19. Costa P, Lobo JMS. Modeling and comparison of dissolution profiles, European Journal of Pharmaceutical science, 2001; 13:123-133.

20. Alam A. et al. Formulation and Evaluation of Pharmaceutically Equivalent Parenteral Depot Suspension of Methyl Prednisolone Acetate. Indian J Pharm Sci. 2009; 71(1):30-34.

21. J. Mulhbacher, P. Ispas-Szabo, M.A. Mateescu. CrossLinked High Amylose Starch derivatives for Drug Release, Swelling Properties, and Mechanistic Study. Int. J. Pharm. 2004; 231-8.

22. International conference on harmonization of technical requirements for registration of pharmaceuticals for human use. Stability testing of new drug substances and products Q1A (R2). 4th version, 200.

23. Mazzo DJ: The ICH stability guidelines, Interpharm press, Inc:p, 2003, 1-30. 